\title{
Global teachers as global learners: Intercultural teacher training in international settings
}

\author{
Sabine Little* - University of Sheffield, UK \\ Michelle Golledge - International School of Stuttgart (ISS), Stuttgart, Germany \\ Hina Agarwalla - Institut Montana Zugerberg, Zug, Switzerland \\ Ben Griffiths - Shanghai United International School, Shanghai, China \\ Danny McCamlie - ALBA International School, Myanmar
}

\begin{abstract}
The globally mobile teacher is a relatively new concept. This article draws on the experiences of seven teachers teaching in international contexts, who are currently undertaking an iPGCE (International Postgraduate Certificate in Education) - four of whom are co-authors of this article. Drawing on original data from written narratives and online discussions, as well as using collaborative writing as a form of inquiry, we locate these experiences within the field of intercultural education, problematize the notion of global mobility and identify the unique training needs of an emerging breed of teachers.
\end{abstract}

Keywords: intercultural education; global mobility; professional development; teacher training; teacher pathways

\section{Introduction}

The globally mobile teacher is a relatively new concept and, as Bunnell (2016) argues, largely under-researched, despite the number of international schools increasing by 150 per cent between 2000 and 2013 (Walker, 2015). While Reid and Collins (2013) explored the complex trajectories of internationally mobile teachers, further research is needed to understand their professional developmental pathways, training needs and identities.

This article draws on the experiences of seven teachers teaching in international contexts, who are currently undertaking an iPGCE - four of whom are co-authors of this article. Unlike national-level programmes, the iPGCE attracts students with a considerable range of teaching experience, most already working in classrooms in various settings and often with a globally mobile background. Given such diverse contexts, teacher training programmes cannot possibly adopt transmission-style pedagogy, when, as teachers in Hacohen's study point out, 'the norm is a flux of change' (Hacohen, 2012: 120). Since both teachers and pupils are caught in this change, teachers arguably have a responsibility in helping students maintain a sense of stability (Hansen, 2011). Being able to do so requires culturally responsive methods that acknowledge the specific needs of such a teacher population; the iPGCE programme aims to assist teachers in critically exploring their own contexts from academic, policy-related and practical perspectives, to identify training and development needs. Simultaneously, the student body on the (largely online) programme forms an invaluable resource in 
itself, creating opportunities for exchange and discussion that may greatly assist in the development of teachers in international, intercultural and multilingual contexts.

This article seeks to address the following questions:

1) In what ways does the teachers' globally mobile background link to their understanding of, and approaches to, intercultural education?

2) How can a teacher education environment help facilitate the development of globally mobile, interculturally competent teachers?

Through these research questions, we explore, in particular, the notion of global mobility as both a geographical and a mental state. Using collaborative writing as a method of inquiry (Richardson, 2000), this article is co-authored by four teachers and students on the programme and the programme director, using data from reflective messages posted on the programme's online discussion board and personal, reflective accounts from the authors, further drawing on some anonymized data from the full iPGCE cohort, illustrating the origins and trajectories of current iPGCE students. The study made a valuable contribution to the definition of global mobility, and the findings significantly drive forward discussion of globally mobile teachers' training and development needs.

\section{Exploring the terminology}

Throughout the literature, terminology within the context of intercultural education varies considerably. Holm and Zilliacus (2009), for example, argue that the terms intercultural and multicultural education are largely used synonymously, although the term 'intercultural' appears more focused on 'interactions, negotiations and processes' (Gundara, 2000: 233), whereas 'multicultural' is more typically viewed as an awareness of cultural, social and linguistic diversity, which also includes aspects of social justice (Nieto, 2004), an aspect also included in Banks's (2017) definition of citizenship education. Savva and Stanfield (2018) argue that the terms multiculturalism and interculturalism are rooted within the concept of nation states and that the term 'international-mindedness', which pervades international schooling literature, is based on a notion of privilege, an aspect we explore further in the conclusion. Gay (2002: 106) refers to 'culturally responsive teaching' as 'using the cultural characteristics, experiences and perspectives of ethnically diverse students as conduits for teaching them more effectively'. Within the context of the iPGCE programme, Gay's (2002) definition therefore refers to both the environment the teachers work in and the environment the programme adopts as a whole, with the usefulness of the latter in developing the former being the focus of this article. Much of the literature in the field originates from diverse classrooms in specific national contexts and comparative education approaches (see, for example, Banks, 2017; Darling-Hammond and Lieberman, 2012), with the international schooling context providing a growing field (see, for example, Savva, 2017; Savva and Stanfield, 2018). The data and literature in this article make reference to intercultural and multicultural awareness, competence and education, in each case taking the original term from data and the literature. We view these terms as part of a multilateral network, with awareness and competence being both precursors of, and contributors to, intercultural education.

Within the context of intercultural education comes a focus on teachers' and students' intercultural awareness and competences. Paris (2012) defines the term intercultural competence in teachers as the ability to be aware of, accept, integrate and expand upon cultural differences in order to ensure that students experience 
meaningful learning. Both Banks (2004a) and Seeberg and Minck (2012) use the term 'cultural competence' to refer to the reduction of prejudice, empowerment and equitable education, Seeberg and Minck (2012) explicitly include pro-social justice action, implying that culturally competent individuals are not just accepting and respectful of other cultures, but are actively seeking to change the status quo - we will later argue that this may be more problematic in some contexts than in others. The authors in Banks (2017: ix) explore the concept of citizenship education from a variety of national and international angles, continuously seeking to balance 'unity and diversity'. As Smolcic and Katunich (2017: 56) point out, 'developing intercultural competence within teachers is a multifaceted and dynamic endeavor' and, arguably, an endeavour best pursued in an intercultural teacher training context. The teachers on the iPGCE programme thus, for the purposes of this article, occupy two distinct spheres within the context of intercultural education - on the one hand, their professional context, where they are viewed as enablers of intercultural education, and on the other hand, as learners themselves in an intercultural teacher training programme, which seeks to facilitate intercultural exchange and problematization of the teacher role in this context. The title of our article, 'Global teachers as global learners', reflects this dual space, unintentionally echoing Pike and Selby's (1988) book Global Teacher, Global Learner, but providing a different focus.

\section{The iPGCE programme}

The iPGCE which forms the basis of this research is a largely online teacher training programme run by a British university. The programme draws its students from a multitude of international backgrounds, including practising teachers without formal qualifications, teaching assistants and volunteers in schools hoping to become teachers in the future. The vast majority of students work in international contexts, across a wide range of age and subject sectors. The programme has a strong collaborative and reflective element, encouraging students to set their own assignment titles commensurate with their personal and professional development needs, and to view other students on the programme as peers, collaborators and potential resources. Since there is no such thing as a global 'licence to teach', the programme is unable to award qualified teaching status within any national context. Fully problematizing the notion of what being a 'qualified teacher' means in the international context is beyond the scope of this article; however, the programme facilitates teachers to gain a strong theoretical background directly related to their professional experience. Throughout the year-long programme, weekly reflective discussions take place on a variety of topics, many of which are either explicitly linked to intercultural education or develop such links through student contributions.

\section{Intercultural education and identity in global classrooms}

Working in an international schooling context questions to what extent 'international education' is, in fact, intercultural education. Hayden et al.'s (2000) 1,400 student and teacher participants believed that five key traits making students 'international' were international-mindedness, open-mindedness, willingness to cooperate, recognizing individuality rather than stereotypes and being culturally sensitive - traits that span both intercultural and multicultural education (Gundara, 2000; Nieto, 2004). Hayden et al.'s (2000) participants felt that a person could be rooted in one culture, yet still 
be 'international'. Fluency in the language of the host country enabled better social interaction and cultural access.

While increased migration is an aspect that increasingly affects learner migration in all contexts, students in international schools are typically particularly transient. Banks's (2017: ix) summary of the Bellagio Conference in 2002 concludes that citizenship education should equip students to 'function in their nations, as well as in a diverse world society', with several authors problematizing notions of identity and a sense of agency and efficacy in this context (Abu El-Haj, 2007; Eksner and Cheema, 2017; Al-Nakib, 2017). Wang and Brockmeier (2002: 51) see culture and self as interdependent, positing that a postmodern social-interactionist perspective has eroded the traditional view of the self as 'strong, independent and unified': even 'cultures [themselves] bleed and permeate into one another' (Bhatia and Ram, 2001: 306).

Sears (2011: 73) explores the narrative of students' multiple identities, linked to the 'shifting, fragmentary and discontinuous nature of a mobile lifestyle'. Bhatia and Ram (2001) note the complexities of such multiple identities. Intercultural education here includes the need for an awareness of how identity, culture and language link together. Teaching in such a context, and being aware of the multiple cultural needs of learners, is arguably specific to the international school context, necessitating further exploration. Lindsey (2004) suggests the creation of a teacher 'cultural biography', proposing that teachers follow in their students' footsteps to understand the intricacies of identity development, an approach mirrored in this study.

\section{The globally mobile teacher}

Elmeroth (2009) highlights the need for teachers who can act as positive role models in fostering multicultural tolerance. It is here that differences between multicultural awareness and intercultural education come to the fore, since a simple nod to, or knowledge of, diverse cultures will not address these needs. Yang and Montgomery (2013) argue that theoretical knowledge and practical integration of that knowledge may not be the same, a position further explored by Savva (2017) in her work with Anglophone teachers working in overseas contexts. While Savva (2017) focuses her study on teachers both born and raised in Anglophone countries, the iPGCE student body is more diverse, opening opportunities for intercultural education as part of the programme design.

Globally mobile teachers, through their experience of working in multiple countries, are arguably better equipped to effectively engage with students from varied backgrounds and play an essential role in inducing both cultural awareness and sensitivity in students (Moule, 2012). They may help reduce prejudice (Yang and Montgomery, 2013: 36) and, as a result, promote 'acceptance, respect for and appreciation of cultural diversity' (Minick and Seeberg, 2012: 5).

The cultural competence referred to by Banks (2004a) and Minick and Seeberg (2012) may be challenging for teachers to promote if they themselves do not have relevant cross-cultural experiences (Van Reken and Rushmore, 2009), or do not work in contexts that encourage the promotion of cultural competence.

Experiences alone, however, do not necessarily make a person interculturally competent, and not all international experiences are equally diverse. Banks (2004b) emphasizes the significance of teachers' dispositions to become culturally responsive. Teachers with personal beliefs concerning race hold differential expectations about their students, which could impact their behaviour towards their students (Pohan, 1996). 
Since teachers' attitudes are reflected in daily educational practices, these must, therefore, be taken seriously and addressed through programmes that address the notion of intercultural competence as part of intercultural education, which potentially includes the role of such programmes as the iPGCE.

\section{Teacher training in international schools}

Pohan (1996: 67) states that teacher training programmes need to address teachers' beliefs surrounding diversity, otherwise 'it is unlikely that schools will ever meet the challenge of equity and excellence for all students'. Questions around what teacher education should encompass differ between national contexts (Darling-Hammond and Lieberman, 2012) and the concept of intercultural education is discussed in national (see, for example, Banks, 2017) and international contexts alike (Savva, 2017). Any programme aimed at globally mobile teachers will, therefore, need to help teachers examine and reflect on their values, and how these relate to their professional context. Sleeter (2008) draws attention to the ever-expanding demographic divide between teachers and students, and emphasizes the importance of this for teacher training programmes.

Professional development and training, including the exploration of one's own cultural identity, play an imperative role in developing intercultural sensitivity (Lindsey, 2004), a precursor to intercultural competence. Brown's (2013) research, though, pinpoints that the distinctive culture of international schools raises concerns relating to teacher efficacy and student achievement, with educators often having limited professional development opportunities, owing to distance and teaching schedules. Furthermore, many education programmes do not focus specifically on intercultural education.

Onafowora (2005) states that new teachers in an international environment usually possess low self-efficacy and confidence levels. In response, she suggests pairing novice teachers with more experienced teachers, building a collaborative model. While school leaders are responsible for providing professional learning opportunities, pedagogy improves significantly when teachers are supported in establishing internal networks, facilitating collaboration (Peckover et al., 2006). When educators collaborate, their academic content knowledge grows and students' achievements improve (Colbert et al., 2008). Such collaboration is crucial in enhancing teacher efficacy, creating a culture of inquiry among teachers (Zeichner, 2003) and is essential in forming effective professional development (Mills and Donnelly, 2001). Since not all schools are able to facilitate such pairings, the iPGCE's collaborative format seeks to facilitate similar networks among its students, an element of the programme this study sought to explore.

\section{Methodology}

\section{Writing as inquiry}

This article combines both traditional data collection (in the form of reflective narratives and discussion board entries) with collaborative writing as a form of inquiry. Both methods expand on Dewey's (1933) notions of open-mindedness, responsibility and wholeheartedness, as being both prerequisites and integral to reflective practice. The process of writing itself can be 'a method of discovery and analysis' (Richardson, 2000: 923) or, indeed, 'a way of "knowing"' (ibid.). Since we argue that career pathways and 
development needs of teachers in international contexts are individual and diverse, it is worth pursuing teachers' individual stories in detail, aiming for in-depth insights, rather than generalization (Hoepfl, 1997). Such studies bring a different kind of rigour and contribution to knowledge, claiming not representativeness, but instead aiming for trustworthiness (Lincoln and Guba, 1985), and offering a more detailed understanding of contexts that may be transferable to other settings (Hoepfl, 1997). Understanding individual lives forms an important aspect of the research process since, as Goodson (1981: 69) argues, 'In understanding something so intensely personal as teaching, it is critical we know about the person the teacher is.'

Collaborative writing has the power to change academic spaces (Speedy, 2012), particularly with contributors from different professional and cultural spheres. The collaborative partnership involved in this research, from inception to writing, allowed us to explore the multifaceted views and experiences of a total of seven teachers working in multicultural, global contexts, while facilitating varying degrees of involvement, that was dependent on the students' preference and availability.

\section{Data collection and analysis}

None of the data included in the article formed part of the assessment or compulsory contribution to the programme. Following the call for papers for this special issue, students were approached by the programme director and invited to collaborate on a study outside the programme's assessment criteria. Four students expressed an interest in becoming involved as co-authors and engaging in the collaborative writing process. Three other students decided to contribute data only, in the form of reflective narratives (six participants in total) and online discussion contributions (seven participants in total).

The data collection included narrative, self-authored responses to prompts relating to three themes directly relevant to the research questions. These themes linked to global mobility (career trajectories to date and future ambitions), intercultural education (defining and providing examples from school contexts) and training needs (exploring intercultural education as a viable teacher training context). The six narratives ranged in length from just under a side of A4 to two sides of A4, mirroring Lindsey's (2004) notion of a teacher 'cultural biography'. Accompanying discussions took place on the programme's online learning environment, exploring the above themes further and providing additional reflective data. Seven students (the six who completed the narrative and one other) took part in these discussions. This sample of seven students is linked to ten different national contexts, by origin (five European, one Asian and one African), or by current teaching location (two teaching in Asia, five in Europe). None teach in the country of their birth. The 37 students in the overall cohort teach in 22 different countries, with four teaching in the country of their birth and education. One participant pointed out that identifying 'origin' can be difficult for globally mobile individuals.

Although the focus of the research was on individual narratives, drawing out key findings of interest to others and of wider significance was a core intended outcome of the study, since 'narratives don't speak for themselves' (Riessman, 2008: 3). The narrative prompts thus provided a framework for thematic analysis, exploring career pathways and understanding of intercultural education and development needs. Further codes emerged from the data, extending the framework through themes on identity and insider/outsider tensions that teachers experienced in their professional contexts. In the findings, codes are grouped together for brevity's sake, drawing on relevant direct quotes where appropriate. 


\section{Ethics}

Research spanning international contexts is inherently difficult to construct and conduct ethically. The study received ethical approval, and discussions and narratives were collated separately from those linked to learning, teaching and assessment on the programme. While this means that many useful contributions could not be included, it ensures all entries were used with full consent from contributors.

Through the study, it emerged that teacher-students' views - particularly in relation to intercultural education - were politically charged in several contexts. This necessitated a careful balance between 'which secrets to keep, and which truths are worth telling' (Ellis, 2007: 26) and provided further practical context to Banks's (2017) notion of the role of education in giving learners a sense of political efficacy. The learners, in the context of this article, are first and foremost the teachers, and our approach highlights a potential difficulty in giving teachers working in international contexts a voice and a sense of agency, without employing the anonymous lens of an external researcher. The professional and personal reputations of all participants (including co-authors) was a vital ethical responsibility. Therefore, we have decided to present findings outside specific national contexts, with participants (including co-authors) numbered 1 to 7 , without explicitly providing national contexts, to aid anonymity.

\section{Limitations}

The small data pool is undoubtedly a limitation, if the purpose of the article were to generalize indiscriminately. By drawing together teachers' narratives from a variety of international teaching contexts, we are in danger of homogenizing a complex field of both research and practice. However, the focus on personal narratives allows personal perspectives and experiences to speak for themselves.

We are aware that the focus on one individual programme holds a bias at two specific levels: on the one hand, an obvious limitation in terms of access to a wider sample (and a potential bias towards the quality of this programme), and on the other hand, the fact that students already on the programme obviously must have identified some need in order to enrol in the first place, thus preventing us from gathering data from teachers not engaged in continued professional development. In working together, we have discussed and challenged our respective views, acknowledging that, while bias cannot be completely removed, it can be ethically and critically examined and scrutinized, a practice we adopted throughout.

\section{Findings}

\section{Student teacher experiences and career pathways}

'My teaching career took more of an unconventional route' (Participant 3, narrative) was an opinion shared by all seven participants of the study, as all followed non-traditional routes into teaching, and this is indicative of the programme as a whole. Gaining experience in teaching before pursuing formal training (Guskey, 2000) was common among the participants. Their career trajectories varied, with previous roles ranging from working at 'an inner-city comprehensive in London' (Participant 1, narrative) to 'tutoring for a nationwide network of learning centres' (Participant 5, narrative) and a role in project management (Participant 6). 
All participants considered themselves to be 'globally mobile', with mobility being due to family upbringing (Participants 1,3), marriage (Participants 2, 4,5) and other professional expertise (Participant 6). In some cases, while the final move may have been instigated by one particular event, participants saw themselves as globally mobile prior to this, for example, through living abroad as part of university studies (Participants 2,3). Only two of the participants were globally mobile as children, again a percentage which is roughly representative of the programme as a whole. Returning to literature around identity and the mobile lifestyle (Sears, 2011; Bhatia and Ram, 2001), these experiences are arguably different for adults and children, as Participant 3 stated: 'having been raised this way, the process of uprooting every six months had become normalized from my perspective'. Exploring in depth the experiences of child mobility may be useful in understanding the teacher's role in intercultural education.

All but one of the participants mentioned self-descriptors which match the cultural competence identifiers developed by Banks (2004a) and Minick and Seeberg (2012), for example 'always being interested in and open-minded towards other cultures' (Participant 5, narrative) and 'become part of the "movement of change"' [making a positive difference through education] (Participant 4, narrative). These cultural competence identifiers were referred to both as motivators to enter intercultural education as a profession and to participate in a teacher training programme modelled on intercultural education principles.

While most students on the iPGCE have existing cross-cultural experiences, allaying the concerns expressed by Van Reken and Rushmore (2009), they may not necessarily be able to facilitate these experiences in their learners (Yang and Montgomery, 2013). Two participants cited knowledge of schools seeking to limit any teaching that could ostensibly be linked to politics, including diverse world views, thus explicitly undermining the notion of intercultural education. While the experiences expressed by the iPGCE student teachers suggest that being globally mobile is as much an attitude as a logistical experience, they also highlight the need for further problematization of the extent to which their interpretation and experience of intercultural education on the programme translates to practice.

\section{Relationship between teacher background and teaching practice}

Intercultural education featured in numerous participants' childhood experiences: 'I did receive my fair share of intercultural education in bits and pieces and learned to appreciate diversity from a very early age' (Participant 4, narrative). This in turn has had positive effects on Participant 4's teaching approaches: 'I ensure that students from different nationalities get equal opportunities to share their views that have been developed, over the course of time, as part of their cultural identity' (Participant 4, narrative). Participant 3 also refers to channelling her own childhood experiences in her teaching, echoing potential differences between those teachers who were globally mobile in childhood and those who became so as adults. Participant 1 references developing intercultural competence as part of teaching in a diverse context in London, showing that geographical global mobility is not always necessary to develop mental global mobility:

this experience [of teaching in London] further developed my understanding of other cultures and in the melting pot that is London, how different cultures work together to [create] a common shared culture. (Participant 1, narrative) 
Participant 5, who had no strong travelling background before moving because of marriage, similarly points to cultural awareness as an ethos and a precursor motivation to join intercultural education:

Given the two [hypothetical] opposing scenarios of an ethnically diverse faculty and student cohort learning a narrow, insular curriculum, or a fairly un-diverse faculty and cohort learning an internationally-minded curriculum ... I would see the latter as having a greater claim to being 'intercultural education'. (Participant 5, narrative)

Contrary to Brown's findings (2013), most participants acknowledge that their specific schools had 'a culture of understanding and support for the learning of other cultures' (Participant 6), although, as outlined earlier, several knew of less inclusive contexts. For participants, language played a valuable role in becoming interculturally competent. Participant 5 acknowledged that language acquisition during formal education was valued and combined with exchange programmes, forming the basis of personal intercultural education. Participant 3 was raised in a country that has 12 official languages, and regards language as instrumental to intercultural competence; a view echoed by Participant 2, who views 'languages [as] the basis for being interculturally educated' (Participant 2, narrative), in line with points about the importance of language made by Savva (2017). These participants incorporate their linguistic skills in their teaching. The findings show that having a multicultural background feeds positively into intercultural pedagogy, but that this multicultural background may be arrived at via multiple routes, linking to Lindsey's (2004) reasoning that personal cultural identity plays a pivotal role in the forming of intercultural competence.

\section{Requirements of teacher education and development in the globally mobile context}

To emphasize the necessity of developing intercultural competence, Participant 1 states that they 'see intercultural education as an integral part of education that should be happening in all contexts' (Participant 1, narrative). This statement aligns with Sleeter's (2008) identification of teachers' intercultural training needs. Since none of the iPGCE students teach in the country of their birth, this is particularly relevant and makes the case for developing teacher training programmes that not only help students develop intercultural competence, but that do so through a model of intercultural education. Participant 6 began teacher training in the UK before moving on to teach internationally. They problematize the notion of being a 'qualified teacher' (that is, holding qualified teaching status for a specific educational context) by contrasting it with being an 'experienced teacher', stating that 'I am very privileged to be in a position that more often than not is based more on what I can do for the school and the pupils, rather than being a qualified or unqualified teacher' (Participant 6, narrative).

Onafowora's (2005) suggestion of pairing teachers of varying confidence and experience is reflected in Participant 4's views, who believes that 'as a human race, our true strength lies in versatility and in learning from each other' (Participant 4, narrative). This approach enables collaboration between educators, which is an important feature in personal development and on the iPGCE, where students have a wide range of experiences that they are encouraged to share and reflect upon.

The participants agreed that the 'sharing of views and informed opinions is an integral part of being an online learner' (Participant 4, online discussion), and the online platform thus facilitates the culture of inquiry advocated by Zeichner (2003), 
allowing students to engage and collaborate with each other in a way that was viewed as beneficial to the learning process for a global teacher. Students commented that:

to hear perspectives from different cultures ... the distance may actual [sic] promote closeness in the relationships with peers in a way that may not happen with day-to-day work colleagues - you can be honest in saying some things (potentially critical of your own school) that you might be reticent to share with those teaching in the same school. (Participant 1 , narrative)

These findings support the argument that an online mentoring and educational programme can be beneficial to the learner and their careers (Gutke and Albion, 2008; Hunt et al., 2013), especially for a course designed to encourage the development of a globally mobile teacher, where cultural competence and exposure to a range of opinions and perspectives is beneficial to the ever-changing work environment (Hacohen, 2012). The opportunity to personalize the programme according to development needs was highlighted as a strength among all participants, showing that the diverse learning needs of teachers in intercultural contexts must be met with equally diverse and intercultural training solutions.

The sense of community, and the ability to discuss issues, provides valuable resources for learners. Facilitating a culturally diverse online community, the programme enables intercultural education by exposing students to an array of opinions and experiences, and is described as 'exactly what students like us need ... exchange of experiences and informed opinions' (Participant 4, online discussion).

While the flexibility to choose one's own assignment titles was seen in a positive light by all participants, in terms of learner autonomy and motivation, it did somewhat hamper the opportunities to engage in intercultural discussions, since 'it becomes harder to collaborate or share ideas' (Participant 5, online discussion) as there is little convergence among student topic choices. The role of the programme director is therefore to help students identify common ground, despite apparently disparate topics and/or settings, highlighting that elements of intercultural education may transcend subject and age boundaries, and ensuring that collaboration can continue to benefit students in their development as teachers.

\section{Conclusion}

This study seeks to explore the histories and contexts of globally mobile teachers and their role in intercultural education, adding to the existing knowledge base by focusing on development needs and, by extension, discussing features of suitable teacher development programmes. Nearly all participants in the study have family links to global mobility, either through upbringing or marriage, with global mobility occurring prior to teaching rather than because of teaching, although in most cases global mobility occurred in adulthood rather than childhood. Nevertheless, career trajectories are vastly different, and it is important to understand that, while cultural awareness of one's own biography (Lindsey, 2004) can help with identity development among teachers, it does not necessarily follow that being globally mobile automatically equips a teacher to develop intercultural competence, or to work successfully in intercultural education. 


\section{Problematizing global mobility}

The central notion of global mobility is not without problems. Although all participants in the study are teaching outside their countries of birth, and so had necessarily been mobile at some point, two participants have been in the same location for over a decade, and two more for nearly a decade. Were they still globally mobile or had they now become settled? Through our discussions, it became clear that all co-authors considered themselves to be globally mobile and viewed global mobility as a state of mind as well as a geographical occurrence. While the latter may have been a single move a long time ago, the former maintained the globally mobile state. It became clear that we all knew (geographically) globally mobile people who were not mentally globally mobile, instead participating 'in the sport of International school hopping' (authors, email discussion). We argue that this expanded interpretation of global mobility may be an alternative to the critique on 'international-mindedness' offered by Savva and Stanfield (2018), in that it speaks to a mental transience and agility on the teachers' behalf, a willingness to constantly question and adapt in international teaching contexts, viewing intercultural education as being in flux and requiring ongoing reflexivity and engagement.

In providing training programmes for globally mobile teachers, then, maybe the most distinguishing feature between students is not the sector they teach in, the subject they teach or the country they are in, but whether they are merely geographically globally mobile or attitudinally globally mobile. The success of a teacher development programme such as the iPGCE rests ultimately on tenets not dissimilar to the definitions of cultural competence introduced by Banks (2004a) and Minick and Seeberg (2012), since students on the programme must be culturally competent in order to work effectively in their global contexts. Intercultural awareness alone is not necessarily enough to span an experiential, cultural divide between teachers and their students (Sleeter, 2008), and professional development programmes that themselves model intercultural education and facilitate global teachers to become global learners. As such, through discussions and assignments, students are asked to challenge and develop their teaching through collaborative conversations with peers working in different intercultural contexts. The reflective approach adopted both in the programme itself and through the collaborative writing of this article hold opportunities for teacher development in all teacher training contexts, both national and international. Flexibility in programme design and culturally sensitive parameters of professional development are vital components in making programmes for globally mobile teachers successful.

\section{Notes on the contributors}

Sabine Little is Lecturer in languages education at the University of Sheffield. She directs multiple online distance learning programmes aimed at teachers in international teaching contexts, including the iPGCE. With a research interest in multilingual families and identity formation in multicultural children, her research and teaching regularly commingle.

Michelle Golledge is employed at an international baccalaureate school in Germany, a country where her path towards becoming an English as an additional language teacher started 17 years ago. Growing up in South Africa, a culturally diverse country with 12 official languages, formed her attitude towards cultural awareness and facilitated the implementation of culturally sensitive pedagogy in her classroom. 
Hina Agarwalla is employed at an international baccalaureate school in Switzerland where she teaches English as an additional language and is a grade 12 advisor. She has volunteered for various educational projects for students from lower-income families. She brings with her 16 years of teaching experience at various levels in Pakistan and Switzerland. She is interested in educational psychology and equity pedagogy.

Ben Griffiths tutored and managed in community-based learning centres in the UK and then moved to Shanghai in 2006. There he taught on Sino-foreign undergraduate programmes for nine years, first teaching English and then business and economics. $\mathrm{He}$ is now in his second year, teaching International Baccalaureate economics at an international secondary school, where he is also Head of Grade 11.

Danny McCamlie is the Key Stage 3 Coordinator at ALBA International School in Myanmar and former Assistant Headteacher of The British School of Madagascar. $\mathrm{He}$ has a keen interest in curriculum development for international citizens and pedagogical practices for the development of students in less economically developed countries (LEDCs). He has worked in and developed teacher training programmes in several LEDCs.

\section{References}

Abu El-Haj, T.R. (2007) '"I was born here, but my home, it's not here": Educating for democratic citizenship in an era of transnational migration and global conflict'. Harvard Educational Review, 77 (3), 285-316.

Al-Nakib, R. (2017) 'Diversity, identity, and agency: Kuwaiti schools and the potential for transformative education'. In Banks, J.A. (ed.) Citizenship Education and Global Migration: Implications for theory, research, and teaching. Washington, DC: American Educational Research Association, 327-50.

Banks, J.A. (2004a) 'Multicultural education: Historical development, dimensions, and practice'. In Banks, J.A. and McGee Banks, C.A. (eds) Handbook of Research on Multicultural Education. 2nd ed. San Francisco: Jossey-Bass, 3-29.

Banks, J.A. (2004b) 'Introduction: Democratic citizenship education in multicultural societies'. In Banks, J.A. (ed.) Diversity and Citizenship Education: Global perspectives. San Francisco: Jossey-Bass, 3-15.

Banks, J.A. (ed.) (2017) Citizenship Education and Global Migration: Implications for theory, research, and teaching. Washington, DC: American Educational Research Association.

Bhatia, S. and Ram, A. (2001) 'Locating the dialogical self in the age of transnational migrations, border crossings and diasporas'. Culture and Psychology, 7 (3), 297-309.

Birt, L., Scott, S., Cavers, D., Campbell, C. and Walter, F. (2016) 'Member checking: A tool to enhance trustworthiness or merely a nod to validation?'. Qualitative Health Research, 26 (13), 1802-11.

Brown, J.K.W. (2013) 'Relationship between Teacher Efficacy and Professional Development in International Schools'. Unpublished PhD thesis, Capella University.

Bunnell, T. (2016) 'Teachers in international schools: A global educational "precariat"?'. Globalisation, Societies and Education, 14 (4), 543-59.

Colbert, J.A., Brown, R.S., Choi, S. and Thomas, S. (2008) 'An investigation of the impacts of teacher-driven professional development on pedagogy and student learning'. Teacher Education Quarterly, 35 (2), 135-54.

Darling-Hammond, L. and Lieberman, A. (eds) (2012) Teacher Education around the World: Changing policies and practices. New York: Routledge.

Dewey, J. (1933) How We Think: A restatement of the relation of reflective thinking to the educative process. Boston: D.C. Heath and Company.

Eksner, H.J. and Cheema, S.N. (2017) '"Who here is a real German?": German Muslim youths, othering, and education'. In Banks, J.A. (ed.) Citizenship Education and Global Migration: Implications for theory, research, and teaching. Washington, DC: American Educational Research Association, 161-84.

Ellis, C. (2007) 'Telling secrets, revealing lives: Relational ethics in research with intimate others'. Qualitative Inquiry, 13 (1), 3-29. 
Elmeroth, E. (2009) 'Student attitudes towards diversity in Sweden'. Intercultural Education, 20 (4), 333-44.

Gay, G. (2002) 'Preparing for culturally responsive teaching'. Journal of Teacher Education, $53(2), 106-16$.

Goodson, I. (1981) 'Life histories and the study of schooling'. Interchange, 11 (4), 62-76.

Gundara, J.S. (2000) 'Issues of discrimination in European education systems'. Comparative Education, 36 (2), 223-34.

Guskey, T.R. (2003) Evaluating Professional Development. Thousand Oaks, CA: Corwin Press.

Gutke, H.J. and Albion, P.R. (2008) 'Exploring the worth of online communities and e-mentoring programs for beginning teachers'. Paper presented at the 19th International Conference of the Society for Information Technology and Teacher Education (SITE), Las Vegas, 3-7 March 2008.

Hacohen, C. (2012) '"The norm is a flux of change": Teachers' experiences in international schools'. Educational Psychology in Practice, 28 (2), 113-26.

Hansen, D.T. (2011) The Teacher and the World: A study of cosmopolitanism as education. London: Routledge.

Hayden, M.C., Rancic, B.A. and Thompson, J.J. (2000) 'Being international: Student and teacher perceptions from international schools'. Oxford Review of Education, 26 (1), 107-23.

Hoepfl, M.C. (1997) 'Choosing qualitative research: A primer for technology education researchers'. Journal of Technology Education, 9 (1), 47-63.

Holm, G. and Zilliacus, H. (2009) 'Multicultural education and intercultural education: Is there a difference?'. In Talib, M.-T., Loima, J., Paavola, H. and Patrikainen, S. (eds) Dialogs on Diversity and Global Education. Frankfurt am Main: Peter Lang, 11-28.

Hunt, J.H., Powell, S., Little, M.E. and Mike, A. (2013) 'The effects of e-mentoring on beginning teacher competencies and perceptions'. Teacher Education and Special Education, 36 (4), $286-97$.

Lincoln, Y.S. and Guba, E.G. (1985) Naturalistic Inquiry. Newbury Park, CA: SAGE Publications.

Lindsey, J. (2004) 'Culture's role in teacher identity: Prompting teachers to explore their cultural background'. Action in Teacher Education, 25 (4), 9-13.

Macdonald, J. and Poniatowska, B. (2011) 'Designing the professional development of staff for teaching online: An OU (UK) case study'. Distance Education, 32 (1), 119-34.

Merryfield, M.M. (2000) 'Why aren't teachers being prepared to teach for diversity, equity, and global interconnectedness?: A study of lived experiences in the making of multicultural and global educators'. Teaching and Teacher Education, 16 (4), 429-43.

Mills, H. and Donnelly, A. (2001) From the Ground Up: Creating a culture of inquiry. Portsmouth, $\mathrm{NH}$ : Heinemann.

Moule, J. (2012) Cultural Competence: A primer for educators. 2nd ed. Belmont, CA: Wadsworth.

Nieto, S. (2004) Affirming Diversity: The sociopolitical context of multicultural education. 4th ed. Boston: Allyn and Bacon.

Onafowora, L.L. (2005) 'Teacher efficacy issues in the practice of novice teachers'. Educational Research Quarterly, 28 (4), 34-43.

Paris, D. (2012) 'Culturally sustaining pedagogy: A needed change in stance, terminology, and practise'. Educational Researcher 41, 93-7.

Peckover, R.B., Peterson, S., Christiansen, P. and Covert, L. (2006) 'A constructivist pathway to teacher leadership'. Academic Exchange Quarterly, 10 (2), 136-40.

Pike, G. and Selby, D. (1988) Global Teacher, Global Learner. London: Hodder and Stoughton.

Pohan, C.A. (1996) 'Preservice teachers' beliefs about diversity: Uncovering factors leading to multicultural responsiveness'. Equity and Excellence in Education, 29 (3), 62-9.

Reeve, J. and Halusic, M. (2009) 'How K-12 teachers can put self-determination theory principles into practice'. Theory and Research in Education, 7 (2), 145-54.

Reid, C. and Collins, J. (2013) '"No-one ever asked me": The invisible experiences and contribution of Australian emigrant teachers'. Race Ethnicity and Education, 16 (2), 268-90.

Richardson, L. (2000) 'Writing: A method of inquiry'. In Denzin, N.K. and Lincoln, Y.S. (eds) Handbook of Qualitative Research. 2nd ed. Thousand Oaks, CA: SAGE Publications, 923-48.

Riessman, C.K. (2008) Narrative Methods for the Human Sciences. Thousand Oaks, CA: SAGE Publications.

Savva, M. (2017) 'Learning to teach culturally and linguistically diverse students through crosscultural experiences'. Intercultural Education, 28 (3), $269-82$.

Savva, M. and Stanfield, D. (2018) 'International-mindedness: Deviations, incongruities and other challenges facing the concept'. Journal of Research in International Education, 17 (2), 179-93. 
Sears, C. (2011) 'Integrating multiple identities: Narrative in the formation and maintenance of the self in international school students'. Journal of Research in International Education, $10(1), 71-86$.

Seeberg, V. and Minick, T. (2012) 'Enhancing cross-cultural competence in multicultural teacher education: Transformation in Global Learning'. International Journal of Multicultural Education, $14(3), 1-22$.

Sleeter, C.E. (2008) 'Preparing white teachers for diverse students'. In Cochran-Smith, M., FeimanNemser, S., Mclntyre, D.J. and Demers, K.E. (eds) Handbook of Research on Teacher Education: Enduring questions in changing contexts. 3rd ed. New York: Routledge, 559-82.

Smolcic, E. and Katunich, J. (2017) 'Teachers crossing borders: A review of the research into cultural immersion field experience for teachers'. Teaching and Teacher Education, 62, 47-59.

Speedy, J. (2012) 'Collaborative writing and ethical know-how: Movements within the space around scholarship, the academy and the social research imaginary'. International Review of Qualitative Research, 5 (4), 349-56.

Van Reken, R.E. and Rushmore, S. (2009) 'Thinking globally when teaching locally'. Kappa Delta Pi Record, 45 (2), 60-8.

Walker, G. (2015) 'International education - for saints or sinners?'. International Schools Journal, 35 (1), 10-15.

Wang, Q. and Brockmeier, J. (2002) 'Autobiographical remembering as cultural practice: Understanding the interplay between memory, self and culture'. Culture and Psychology, 8 (1), 45-64.

Yang, Y. and Montgomery, D. (2013) 'Gaps or bridges in multicultural teacher education: A O study of attitudes toward student diversity'. Teaching and Teacher Education, 30, 27-37.

Zeichner, K.M. (2003) 'Teacher research as professional development for P-12 educators in the USA'. Educational Action Research, 11 (2), 301-26. 